\title{
Geomagnetic field variations at the equatorial electrojet station in Sri Lanka, Peredinia
}

\author{
R. G. Rastogi ${ }^{1,2}$, T. Kitamura ${ }^{3}$, and K. Kitamura ${ }^{3}$ \\ ${ }^{1}$ Physical Research Laboratory, Ahmedabad 380009, India \\ ${ }^{2}$ Gujarat University, Dept. of Physics, Ahmedabad 380009, India \\ ${ }^{3}$ Department of Earth and Planetary Sciences, Kyushu University, 33 Fukuoka 812-8581, Japan
}

Received: 31 January 2004 - Revised: 5 January 2004 - Accepted: 9 Febraury 2004 - Published: 7 September 2004

\begin{abstract}
The paper discusses the variations of the horizontal $(H)$, vertical $(Z)$ and eastward $(Y)$ components of the geomagnetic field at Peredinia (PRD), an electrojet station in Sri Lanka, with the time of the day, season, sudden commencement (SSC) and during geomagnetic storms. The daily variation of $H$ showed a large peak around midday. The daily variation of $Z$ appeared to be almost a time gradient curve of the daily variation of $H$, showing a maximum around 09:00 LT $\left(75^{\circ} \mathrm{EMT}\right)$ when the $H$ field was increasing fastest and not at noon when $\Delta H$ was the maximum. Storm time variation of $H$ resembled the variation of the $D_{s t}$ index but that of $Z$ showed a large minimum about 2$3 \mathrm{~h}$ before the time of minimum $D_{s t}$ or at the time of maximum time gradient of $D_{s t}$ variation. These features are compared with corresponding variations at the equatorial stations Trivandrum (TRD) in India, and remarkable similarity in all observations is noticed at PRD and TRD. It is suggested that the observed abnormal features of $Z$ variations at electrojet stations in India-Sri Lanka are due to (i) direct effect of the ionospheric electrojet current (ii) the induction effect of the image current by the average spatially extended conductivity region and (iii) the induction current in the local subsurface conductor. It is suggested that the conductor responsible for the observed features in $Z$ in India and Sri Lanka has to have extended spatial domain to latitudes well south of India, rather than confined to narrow Palk Strait.
\end{abstract}

Key words. Geomagnetism and paleomagnetism (geomagnetic induction; time variation diurnal to secular) - Ionosphere (equatorial ionosphere)

\section{Introduction}

Although the first standard geomagnetic observatory in the world within the region now known as the equatorial electrojet belt was established at Kodaikanal, India in 1901, but

Correspondence to: R. G. Rastogi

(parvs@prl.ernet.in) any scientific results from these early data are not available in open literature. When a geomagnetic observatory was established in 1922 at Huancayo in Peru, an abnormally large daily range of geomagnetic horizontal field, $H$, was noticed by Mc Nish (1937). Plotting the latitudinal variations of the daily range of $H$ at six observatories that existed at low latitudes, three of these in India, Egedal (1947) found an intensification of the daily range of the $H$ field over the dip equator. This phenomenon was described by Chapman (1951) as due to an eastward band of electric currents in the ionosphere which he named as "Equatorial Electrojet". According to the model suggested by him, the geomagnetic horizontal field $\Delta H$ due to the electrojet current should be maximum and the geomagnetic vertical field $(\Delta Z)$ due to the current should be zero over the equator. The results of geomagnetic survey in India by Pramanik and Yegna Narayanan (1952) and by Pramanik and Hariharan (1953) showed the daily peak of $H$ at 11:00 LT at stations close to the equator. Rastogi (2004) showed that their data indicated a maximum of $Z$ in the forenoon and a minimum in the afternoon hours, not expected of the Chapman model of EEJ. The latitudinal survey of the $H$ and $Z$ field in Nigeria by Onmumechilli (1963) and in Central African longitudes by Fambitakoye and Mayaud (1976) showed results in full conformity with expectations on the Chapman model of EEJ.

During the International Geophysical year, a set of five low-latitude stations were established in Peru, the results of the analysis of these data were reported by Forbush and Casaverde (1961). In India, two new observatories were established at Trivandrum (TRD) and at Annamalainagar (ANN), in addition to the already existing observatories at Kodaikanal (KOD) and Alibag (ABG). It was found that the daily range of both $H$ and $Z$ were largest at stations closest to the magnetic equator in India (Yacob and Khanna, 1963). Since 1980, an additional electrojet observatory was established at Ettayiapuram (ETT). These geomagnetic observatories have been supported by a network of ionospheric and optical observatories and by the equatorial rocket launching stations at Thumba. A large number of papers have been 

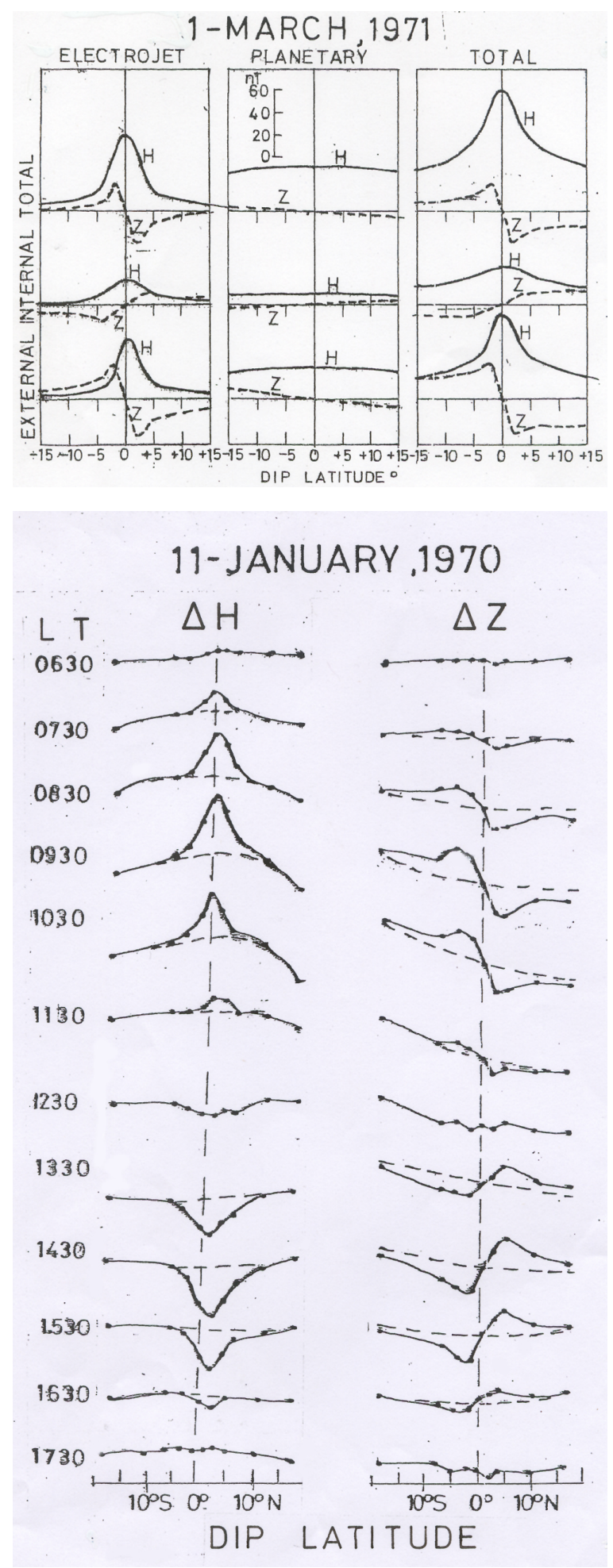

Fig. 1. (a) Latitudinal variations of the total planetary and electrojet components of $\Delta H$ and $\Delta Z$ due to the ionospheric current (external) and the induced current inside the Earth's core (internal) at a network of geomagnetic stations in Ethiopia (after Carlo et al., 1982). (b) Latitudinal variations of $\Delta H$ and $\Delta Z$ at stations across the magnetic equator in Central African region on 11 January 1970 (after Fambitakoye, 1976). published on almost every feature of the equatorial electrojet and counter electrojet and their effects on the ionospheric plasma and the plasma irregularities covering both spatial and temporal aspects. A detailed report on these phenomena is provided by Rastogi (1989).

Indian scientists have always felt the absence of geomagnetic data from any stations south of Trivandrum to fully understand the results from their stations. T. Kitamura of the Kyushu University, Japan had arranged the operation of a portable digital variometer, recording high-resolution data of $H, D$ and $Z$ at a number of locations around the world. One of the stations was Peredinia (Geog. Lat. 7.3 ${ }^{\circ} \mathrm{N}$, Geo. Long. $80.6^{\circ} \mathrm{E}$ ) in Sri Lanka. This station formed a very important link with the network of geomagnetic observatories in India. The data from Peredinia cover a period of about 1.5 year in 1993-1994. This paper describes the detailed analysis of the data from Peredinia.

\section{Daily variations of $H$ and $Z$ at equatorial electrojet stations}

Chapman and Bartels (1940) have given the expression for the magnetic potential of a steady-state current distribution flowing in a thin spherical shell of radius a. At a point $\left(r, \theta_{0}\right.$, $\phi_{0}$ ) the potential $W$ of the whole shall be expressed as:

$$
\begin{aligned}
& W=-4 \pi \sum_{n=0}^{\infty} \frac{n+1}{2 n+1} M_{n}\left(\theta_{0}, \phi_{0}\right)\left(\frac{r}{a}\right)^{n} \text { for } r<a, \\
& W=-4 \pi \sum_{n=0}^{\infty} \frac{n+1}{2 n+1} M_{n}\left(\theta_{0}, \phi_{0}\right)\left(\frac{r}{a}\right)^{n+1} \text { for } r>a .
\end{aligned}
$$

Conversely, the steady-state current due to the magnetic potential $\mathrm{W}=\Sigma \mathrm{Wn}(\theta, \phi)$ is given by

$$
\begin{aligned}
& J_{n}=-\frac{10}{4 \pi} \frac{2 n+1}{n+1}\left(\frac{a}{r}\right)^{n} W_{n} \text { for } r<a, \\
& J_{n}=\frac{10}{4 \pi} \frac{2 n+1}{n}\left(\frac{r}{a}\right)^{n} W_{n} \text { for } r>a .
\end{aligned}
$$

Later Chapman (1951) extended these equations for a thin sheet of current of semi-width $(w)$ over the magnetic equator at a height $h$. The northward $X$, and the vertical $Z$ components of the magnetic field at distance $n$ on the ground surface are given by

$$
\begin{aligned}
& \Delta X=\frac{J}{w} \tan ^{-1} \frac{z w h}{h^{2}+x^{2}-w^{2}} \\
& \Delta Z=\frac{J}{z w} \log ^{-1} \frac{(x+w)^{2}+h^{2}}{\left(x^{2}-w\right)^{2}+h^{2}},
\end{aligned}
$$

where $J$ is the strength of uniform electrojet sheet current.

The Chapman (1951) model of the equatorial electrojet expects that the latitudinal variation of the $H$ field should be maximum at $0^{\circ}$ dip latitude and a continuous decrease on both the northern and southern side of the equator until the 
latitude that defines the edge of the electrojet belt. The latitudinal profile of the $Z$ field shows a zero value at the dip equator with a minimum at the northern and a maximum at the southern edge of the electrojet belt. $\Delta Z$ should return slowly to a low value with further increase of latitude. He also discussed the effect of induced current inside the Earth, assuming that the Earth is a perfect conductor below a depth of $250 \mathrm{~km}$. Thus, the image current has the same magnitude as the external current flowing at a depth of about $600 \mathrm{~km}$ below the Earth's surface, in a direction opposite to that of the source current. The $\Delta H$ which field, due to the external and internal currents, would add up to give the observed $\Delta H$ consisting of about two-third from the external and one-third from the internal current source. The $Z$ fields, due to the external and internal currents, would oppose each other and result in a $\Delta Z$ that would be similar but less in magnitude than due to the external current alone. Other models have been suggested later (Mareschal et al., 1987) but these give basically results similar to that of the original Chapman model. Gouin and Mayaud (1967) described occasional reversals in the solar daily variations of the $H$ field at Addis-Ababa and ascribed it to the westward reversal of the electrojet current named by them as counter equatorial electrojet (CEJ).

A more direct method of estimating the direction of ionospheric currents in the ionosphere over the equatorial electrojet has been through the monitoring of ionospheric drift by HF sounding by spaced receiver technique (Chandra et al., 1971) and VHF backscatter Doppler shift measurements (Woodman, 1970). Horizontal drifts were found to be normally westward during the day and eastward during the night (Chandra and Rastogi, 1969). Rastogi et al. (1971) were the first to show that the electric fields in the ionosphere over the equatorial electrojet region were reversed during the counter electrojet (CEJ) events.

Forbush and Casaverde (1961) showed the presence of anomalous currents induced by the electroject in the Peruvian region from the analysis of ground magnetic variations. The external and internal components of $H$ and $Z$ field were separated by the technique defined by Siebert and Kertz (1957) through the use of the Kertz operator. Data from seventeen field stations in the Ethiopian sector set up $4.5^{\circ} \mathrm{S}$ to $4.1^{\circ} \mathrm{N}$ dip latitudes during 1970-71 were combined with those from permanent observatories by Carlo et al. (1982). The $\Delta H$ and $\Delta Z$ data were separated into external and internal (induced) components. The result of this study for 1 March 1971 are redrawn in Fig. 1a as a typical example.

First of all, it can be seen that the variations of the $H$ field due to the external and internal parts of the electrojet currents were similar, with a maximum over the equator with similar half width. The internal part of $\Delta H$ was found to be $\sim 0.28$ times the external part for the $\mathrm{Sq}(H)$ variations. The latitudinal variation of $\Delta Z$ due to internal current was opposite to that due to the external current. Thus, the induced current increases the value of the observed $\Delta H$ over the equator but reduces the value of $\Delta Z$ at the latitudes near the fringe of the electrojet belt.

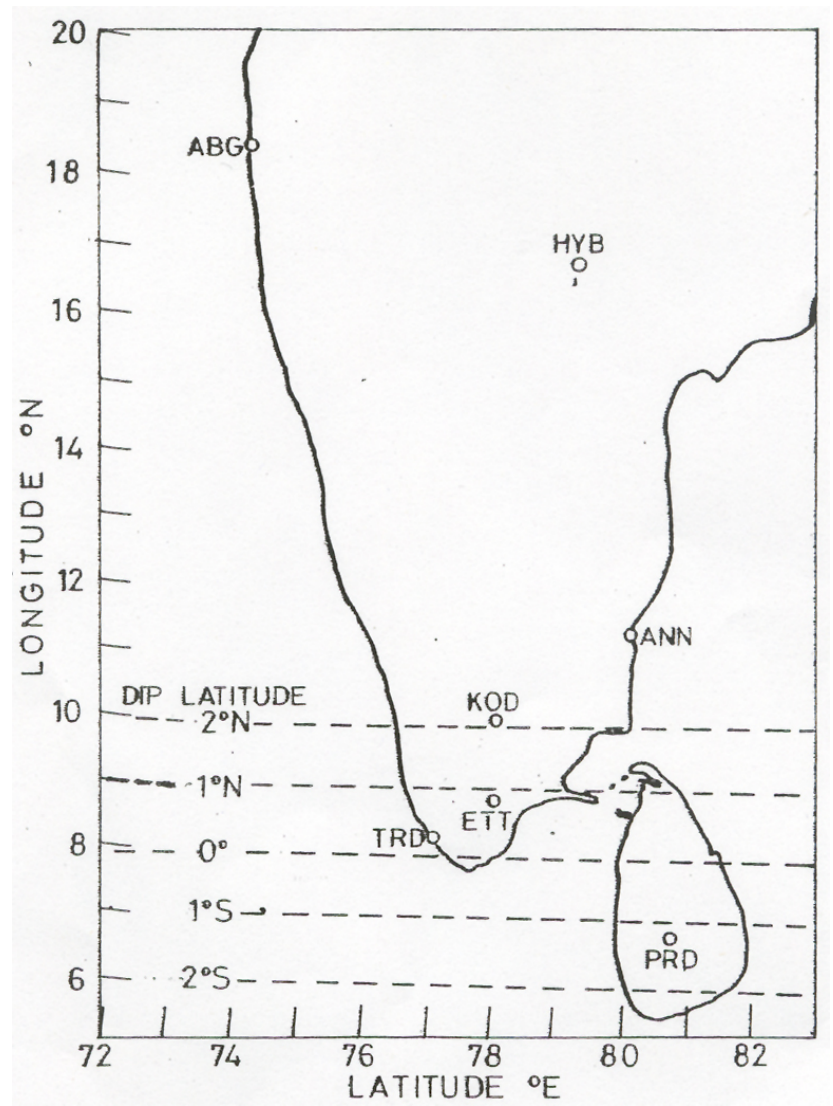

Fig. 2. The map showing the location of geomagnetic observatories and of the iso dip line of $+1,+2$ and 0 degrees in the Indo-Sri Lanka longitude sector. Note that Peredinia is the only observatory in this sector situated south of the dip equator.

The use of the data network of geomagnetic stations across the magnetic equator in Chad, Central African region was the first attempt to study the EEJ on both sides of the magnetic equator on a regular basis. Fambitakoye (1976) described the regular daily variations of equatorial electrojet in the Central African region. In Fig. $1 \mathrm{~b}$ the latitudinal variations of $\Delta H$ and $\Delta Z$ due to $\mathrm{Sq}$ and electrojet currents on 11 January 1970 are shown, which recorded a normal electrojet in the forenoon and a counter electrojet in the afternoon hours. The diagrams are reconstructed after Fambitakoye (1976). It can be seen that the $\Delta Z$ showed a minimum around $3^{\circ} \mathrm{N}$ and a maximum around $3^{\circ} \mathrm{S}$ from 07:30 to 10:30 LT when $\Delta H$ showed a maximum around $0^{\circ}$ dip. During the period 13:30-16:30 LT, when $\Delta H$ showed a minimum over the dip equator, $\Delta Z$ was a minimum in the southern and maximum at the northern $3^{\circ}$ dip latitude.

The ratio of $\Delta Z / \Delta H$ due to Sq or Storm Sudden commencement (SSC) is the index of abnormal electromagnetic induction at the station. The values of $\Delta Z / \Delta H$ at Trivandrum are the highest, sometimes exceeding 1.0 during sfe, SSC and other events (Rastogi, 1999). These inductions, at the present understanding, are supposed to be due to the eddy currents induced in a conductor beneath the Palk Strait 


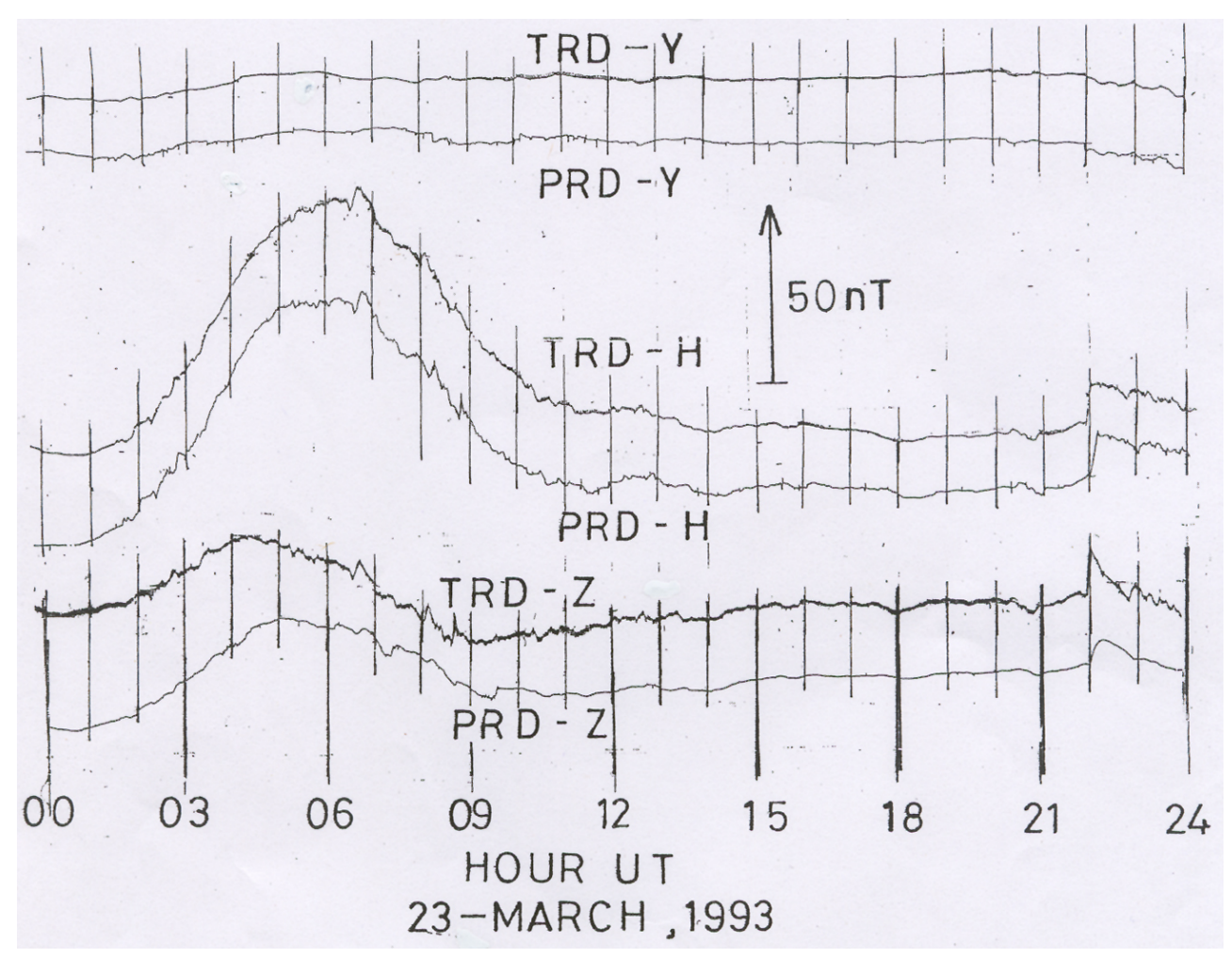

Fig. 3. Comparisons of the magnetograms at Peredinia (PRD) constructed from the digital data and the magnetogram at Trivandrum (TRD) from the ISMIRAN IV magnetometer for 2-3 March 1993.

between India and Sri Lanka. There has been no observation taken at a station south of Trivandrum to confirm the above suggestion. The availability of geomagnetic data of Peredinia, the only known station south of the Indian chain, provides unique data for studying the normal and abnormal variations along the Indo-Sri Lanka lontitude sector.

\section{Data analysis and results, quiet conditions}

In Fig. 2 the position of Peredinia (PRD, dip lat. $\lambda=1.3^{\circ} \mathrm{S}$, dipole lat. $=1.9^{\circ} \mathrm{S}$ ) in relation to the location of the lowlatitude stations in India, Trivandrum (TRD, $\lambda=0.3^{\circ} \mathrm{N}$, Ettayiapuram (ETT, $\left.\lambda=1.1^{\circ} \mathrm{N}\right)$, Kodaikanal (KOD, $\lambda=2.6^{\circ} \mathrm{N}$ ), Hyderabad (HYB, $\lambda=11.3$ ) and Alibag (ABG, $\lambda=13.4^{\circ} \mathrm{N}$ ) are shown. The iso-dip lines of $0^{\circ}, \pm 1^{\circ}$ and $\pm 2^{\circ}$ are also shown in the figure. It can be seen that the station in India which is the closest conjugate to Peredinia is Ettyiapuram and the station closest to the dip equator is Trivandrum.

In Fig. 3 the magnetogram traces of $H, Y$ and $Z$ at Trivandrum provided by WDC at Kyoto, Japan, with the corresponding magnetorgram traces at Peredinia for the 23 March 1993 are compared. It can be seen that the traces of $H, Y$ and $Z$ are remarkably coherent at the two stations, even to finer details. Thus, it is assured that the data from a field observatory at Peredinia is in no way inferior to the data from a permanent standard geomagnetic observatory maintained according to IAGA regulations. The very short time impulses, like sfe and SSC, that can also be studied from PRD data would be discussed later.

Solar quiet day variation of a geomagnetic component, say, $X$, during an individual month denoted by $\mathrm{Sq}$ is generally taken as the mean of the daily variations of $X$ on the five International Quiet (IQ) days of the month. The mean value of $X$ at 00:00 LT is taken as the base line value of $X$ and is subtracted from all the 24-hourly values such that the resulting $\Delta X$ for any hour is associated with the ionospheric current at that hour. The $00 \mathrm{~h}$ and $24 \mathrm{~h}$ values in the so-derived daily variation of $X$ may not be same. This diurnal inequality is removed by taking the difference $X(24)-X(00)$ and subtracting $\mathrm{n}[X(24)-X(00)] / 24$, where $\mathrm{n}$ is the particular solar hour concerned.

First of all, Sq variation of the $H, Y$ and $Z$ fields at each of the stations were computed. Local times were taken as $75^{\circ}$ EMT for Indo-Sri Lanka stations and $45^{\circ}$ EMT for AddisAbaba. Figure 4 shows the yearly mean $\mathrm{Sq}$ variations of $H, Y$ and $Z$ fields at all these stations. As expected, large $\Delta H$ are noticed at three stations close to the dip equator, $\Delta H$ was $87 \mathrm{nT}$ at TRD, $84 \mathrm{nT}$ at PRD and $89 \mathrm{nT}$ at AAE. Also with increasing latitude of the station the daily range in $H$ decreased progressively and it was $71 \mathrm{nT}$ at Kodaikanal (KOD) and $61 \mathrm{nT}$ at ANN. The daily variations of the $Z$ field at KOD and ANN, which are close to the northern fringe of the electrojet, showed a large minimum around midday hours. TRD, as observed from early studies, showed a large amplitude of the $Z$ field, with a maximum in the forenoon 


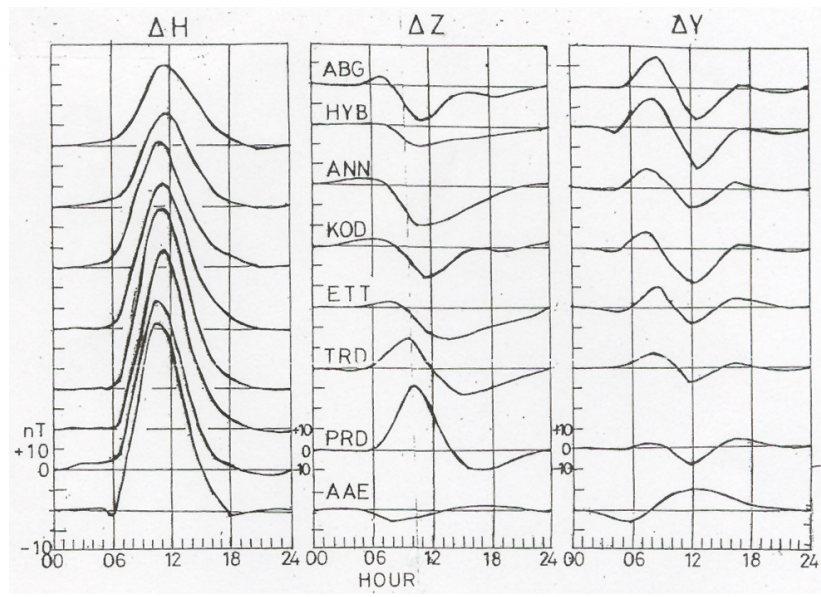

Fig. 4. Yearly mean daily variations of $\Delta H$ and $\Delta Z$ at observatories along Indo-Sri Lanka longitude sector during the period March 1993-February 1994.

and the minimum in the afternoon hours. It is important to note that PRD showed a much larger forenoon maximum of $\Delta Z$ than that at TRD. The abnormally large daily range as known earlier has been suggested as due to induced current in a conductor some hundreds of kilometers below the surface. A spatially uniform conductor would not distort the daily variation $\Delta Z$ according to Chapman's formulae. The induced narrow band of current would also flow eastward and would produce $\mathrm{Sq} Z$ variation opposite to that due to overhead ionospheric current, producing positive $\Delta Z$ at a station north of the underground current band. To justify positive $\Delta Z$ at Trivandrum situated right over the dip equator, the position of the anomalous conducting layer has to be shifted southward and has been suggested to be along the Palk Strait. This model should generate $\Delta Z$ maximum at the same time as the maximum $\Delta H$ and no explanation has been provided for the time and magnitude of $\Delta Z$ maximum at $09 \mathrm{LT}$ and broad minimum in the afternoon hours. Similar but lower in magnitude $\mathrm{Sq} Z$ is seen at ETT while $\Delta \mathrm{Zs}$ at KOD and ANN are little affected by induced current. Rather unexpected of the Chapman model of induction, $\mathrm{Sq} Z$ at Peredinia, situated south of the dip equator, has a much larger forenoon peak. It is further noted that Addis-Ababa (AAE, $9.0^{\circ} \mathrm{N}, 38.8^{\circ} \mathrm{E}$ ), situated almost on the dip equator but in a different longitude zone, did not indicate any abnormal induction effect in Sq Z variation.

The daily variation of the eastward field $Y$ at Peredinia was similar to that at Trivandrum with a forenoon maximum and a midday minimum and is quite different to $\mathrm{Sq} Y$ at AddisAbaba. Rastogi and Stening (2002) have described the daily, and seasonal variations of the $Y$ field at equatorial stations around the world. The definite explanation of the observed variance of Sq $Y$ at different stations still needs identification.

The dip latitude of PRD is $1.3^{\circ} \mathrm{S}$ and that of ETT is $1.1^{\circ} \mathrm{N}$. Thus, in the absence of any abnormal induction effects the daily variations of the $Z$ field at PRD should be similar but

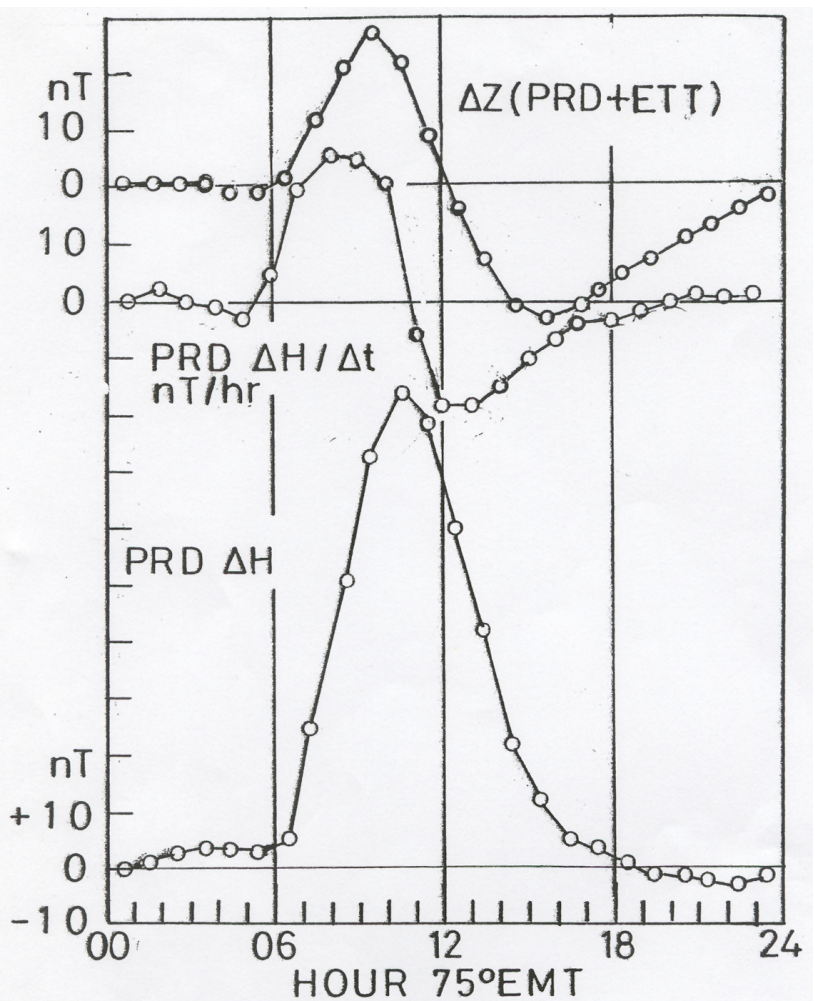

Fig. 5. Yearly mean daily variation of $\Delta H$ and $P R D$ and $\Delta Z$ at $\mathrm{PRD}+\Delta Z$ at KOD compared with the temporal gradient of $\Delta H$ at PRD during the period March 1993-February 1994.

opposite in nature at $\Delta Z$ and PRD should have shown a corresponding midday maximum of $\Delta Z$. Thus, adding $\Delta Z$ at ETT to $\Delta Z$ at PRD would remove the effect of ionospheric current on $\Delta Z$ at PRD and would leave the effect of induction alone. In Fig. 5 the daily variation of $\Delta H, \Delta H / \Delta \mathrm{t}$ and $\Delta Z$ (PRD + ETT) for the year 1993-1994 are shown. It can be seen that $\Delta Z(\mathrm{PRD}+\mathrm{ETT})$ now shows a maximum at 09:30 LT and a equally prominent minimum at 15:30 LT. The temporal gradient $\Delta H / \Delta \mathrm{t}$ shows a maximum in the forenoon and a minimum around 12:30 LT. Thus, $\Delta Z$ at PRD is maximum (positive) when $\Delta H$ PRD is affected by abnormal induced currents inside the Earth to an extent probably larger than that at TRD.

The $H, Y$ and $Z$ data at PRD and TRD were next grouped into three Lloyd seasons of the year. (1) E months, consisting of March, April, September, and October 1993, (2) J months, consisting of May, June, July, August 1993 and (3) D months, consisting of November, December 1993 and January, February 1994. The resultant curves are shown in Fig. 6 . The daily variations of $\mathrm{Sq} H$ during any season were practically the same at PRD and TRD, and it was the largest during $\mathrm{E}$ months and least during $\mathrm{D}$ months. The mean daily variations of $\mathrm{Sq} Z$ during any of the months was larger at PRD than at TRD. The daily maximum of $\Delta Z$ was at later hours at PRD than at TRD. The effects of electrojet current on the daily variations of $Z$ at TRD (dip lat. $0.3^{\circ} \mathrm{N}$ ) was negligible and the observed variation was dominated by 


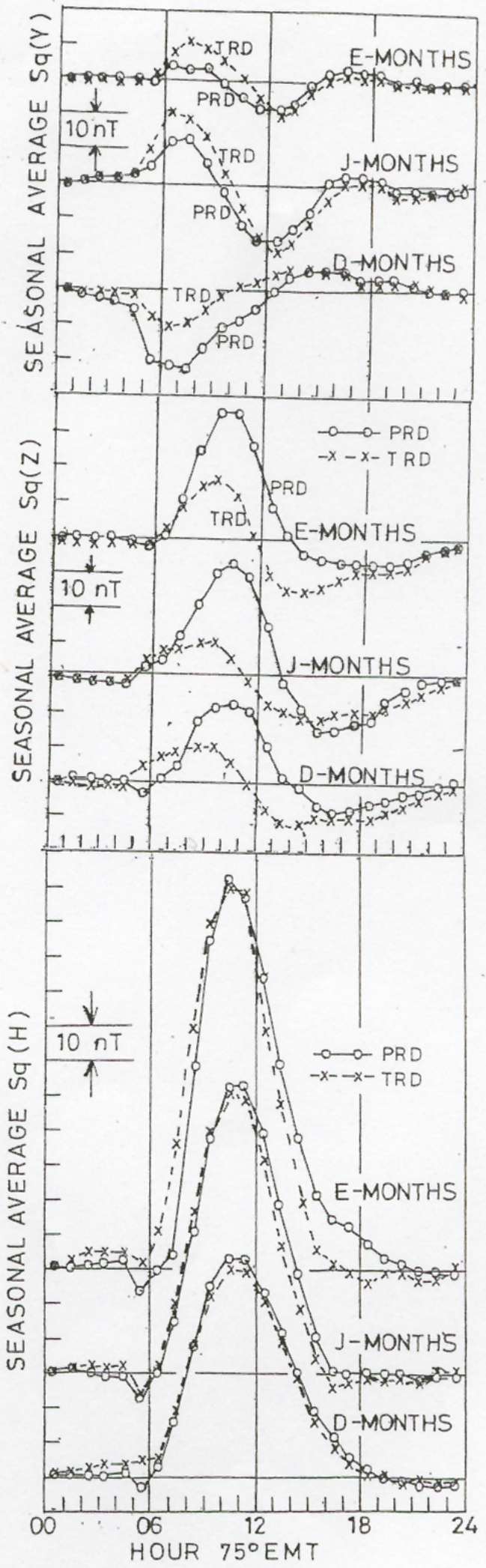

Fig. 6. Seasonal average daily variations of $H, Y$ and $Z$ fields at Peredinia and Trivandrum, during the period March 1993-February 1994. the effect of electromagnetic induction. PRD, being situated south of the magnetic equator, showed that $\Delta Z$ should indicate the effect of the equatorial electrojet with a maximum during the afternoon hours. The observed peak, however, occurred well before noon.

Next, we examine the daily variations of $\Delta H$ and $\Delta Z$ on normal (NEJ) and counter (CEJ) electrojet days in two cases, in Figs. 7a and b. Referring to Fig. 7a it can be seen that all three days of 12, 13 and 14 August 1993 were undisturbed days, as indicated by very low values of $D_{s t}$ index. The $\Delta H$ (TRD-ABG), being negative ( 30 nT) on 12 August 1993 indicates a weak EEJ, while on 13 August 1993, $\Delta H$ (TRD$\mathrm{ABG}$ ) was at a minimum of $-70 \mathrm{nT}$, indicating a strong CEJ. On the other hand, on 14 Aug. $\Delta H$ (TRD-ABG) showed a value of over $50 \mathrm{nT}$, suggesting a NEJ day. On a NEJ day (14 August 1993) $\Delta H$ showed a positive peak around midday at any of the stations and $\Delta Z$ showed a positive peak at PRD. On a CEJ day (13 August 1993), $\Delta H$ showed a large minimum at any of the stations, while $\Delta Z$ was negative in the forenoon hours and positive in the afternoon hours at PRD and TRD.

Figure $7 \mathrm{~b}$ shows variations of $\Delta H$ and $\Delta Z$ at all the equatorial stations on 14 and 15 February 1993. $\Delta H$ (TRD-ABG) had a positive peak of $50 \mathrm{nT}$ around the midday hours on 14 February 1993, indicating a strong NEJ day while it was about $-40 \mathrm{nT}$ around 10:00 LT on 15 February 1993, indicating this day to be a CEJ day. It can be seen that on 14 February 1993 (NEJ day), $\Delta H$ had a midday peak around noon and $\Delta Z$ had a forenoon peak at all stations with the largest magnitude at PRD, decreasing progressively northward. On 15 February 1993 (CEJ day) when $\Delta H$ was negative at each of the station, $\Delta Z$ did not show any positive value around 09:00 LT at PRD and TRD as on normal days, while $\Delta Z$ at KOD and to a lesser extent at ETT showed a positive midday peak predominantly due to the effect of the ionospheric current. Thus, these observations confirm the suggestion of $\Delta Z$ at PRD and TRD being affected by induced currents due to the eastward and westward ionospheric currents.

It is suggested that the daily variations of $H$ and $Z$ on quiet days at equatorial stations along Indo-Sri Lanka longitude sector are due to the combined effects of (i) direct ionospheric current, (ii) image current of the quasi-static part of the ionospheric current (iii) the effect of current, induced in the subsurface conduction anomaly region due to the dynamic time variation of the ionospheric current.

\section{Day-to-day variation of the daily range of $H$ and $Z$}

Next, we studied the interrelations between day-to-day variations of the daily ranges of $H$ and $Z$ at the equatorial stations in India and at Peredinia. The range of $H$ was taken as the difference between the daytime maximum or minimum hourly value of $H$, depending on normal and counter electrojet days and the hourly value at $00: 00 \mathrm{~h}$ on any day. It was positive on a normal electrojet day and negative on a counter electrojet day. The range in $Z$ was taken as the difference 
between the maximum and minimum hourly mean value of $Z$ on a particular day. The period chosen for this study was November 1993 to February 1994.

Figure 8a shows the mass plot of the daily range of $H$ at PRD, ETT and KOD with respect to the corresponding range of $H$ at TRD. As a guidance at $45^{\circ}$ a line is drawn to assess relative changes in the range $H$ at a station with that at TRD. It can be seen that PRD $H$ vs. TRD $H$ is close to the $45^{\circ}$ line, indicating that the day-to-day values of the range of $H$ at the two stations were almost the same. The plot of ETT, $H$ vs TRD $H$ indicate some lower values at ETT with the ratio of range $H$ at the two stations being 0.96. The range of $H$ at KOD was definitely lower than the corresponding value for TRD, the ratio of range $H$ between the two stations was only 0.80 . These results are consistent with the latitudinal variation of range of $H$ within the equatorial electrojet region.

In Fig. $8 \mathrm{~b}$ the mass plots of range $Z$ versus the range of $H$ are shown individually for different stations. It can be seen that at Peredinia range $Z$ increased linearly with the increased range of $H$ with a ratio of about 0.4 . For Trivandrum and Ettaiyapuram, the scatter of points was comparatively larger, with the range of $Z$ tending to increase with range $H$, with a ratio 0.2 and 0.15 . For KOD, the range $Z$ decreased with increasing range $H$, indicating the predominant direct effect of the ionospheric current in relation to the induction effects.

\section{Variation of geomagnetic field during disturbed con- ditions}

\subsection{Storm Sudden Commencement in $H, Y$ and $Z$}

The Sun occasionally emits clouds of highly energized charged particles following the solar flare or due to a coronal hole in the solar atmosphere. The impact of the solar plasma on the magnetosphere compresses the latter causing a sudden increase in the magnetic field called Sudden Storm Commencement or SSC at all low- and middle-latitude stations.

In Fig. 9 the variations of $H, Y$ and $Z$ fields on 11 March 1993 are shown in comparison with the corresponding variation of the Auroral current index, AE. It can be seen that there are sudden impulses in the $H$ field associated with increases in the AE index. The magnitudes of impulses in the $H$ were almost of same magnitude at PRD as at TRD. It is interesting to note that there were large impulses in the $Z$ field at both the stations associated with the impulses in $H$ field. However, unlike the normal quiet days TRD showed larger response. The impulses were also present in the $Y$ field but their amplitudes were small. It is concluded that the sudden impulses in the $H$ and $Z$ fields at PRD are due to induction effects.

\subsection{Storm time variations $H, Y$ and $Z$}

Following the impact of solar plasma on the Earth's magnetosphere during the SSC, some of the charged particles that

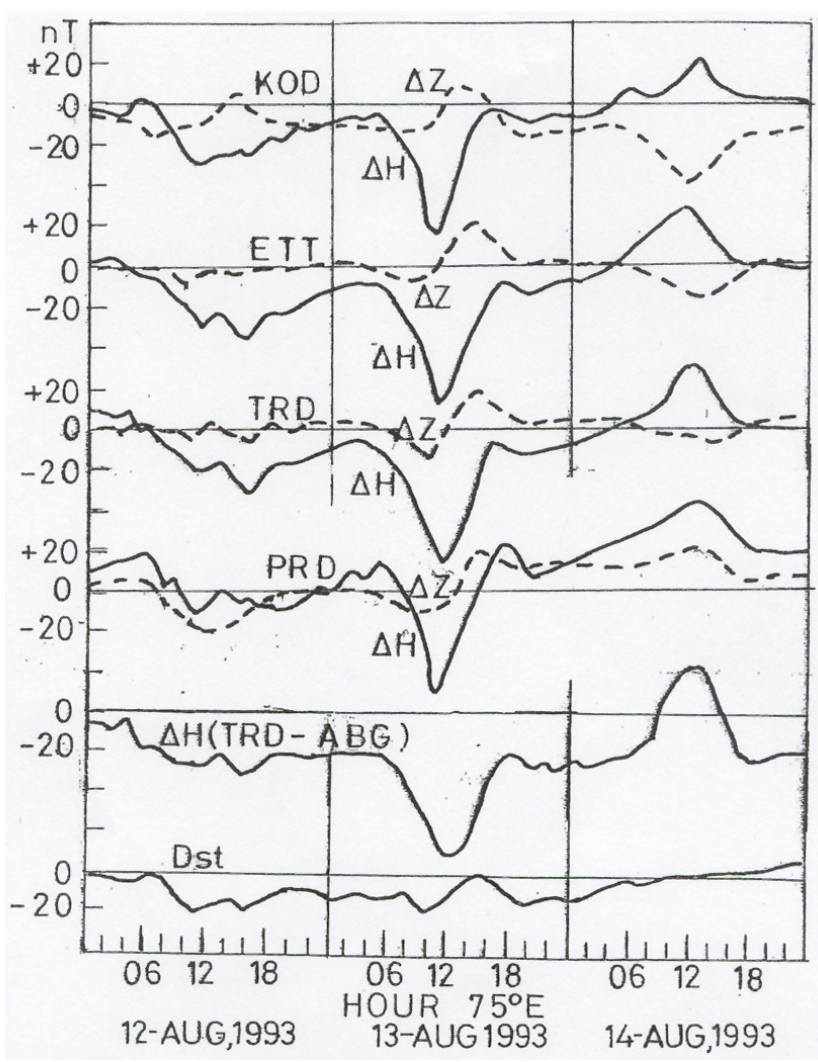

(a)

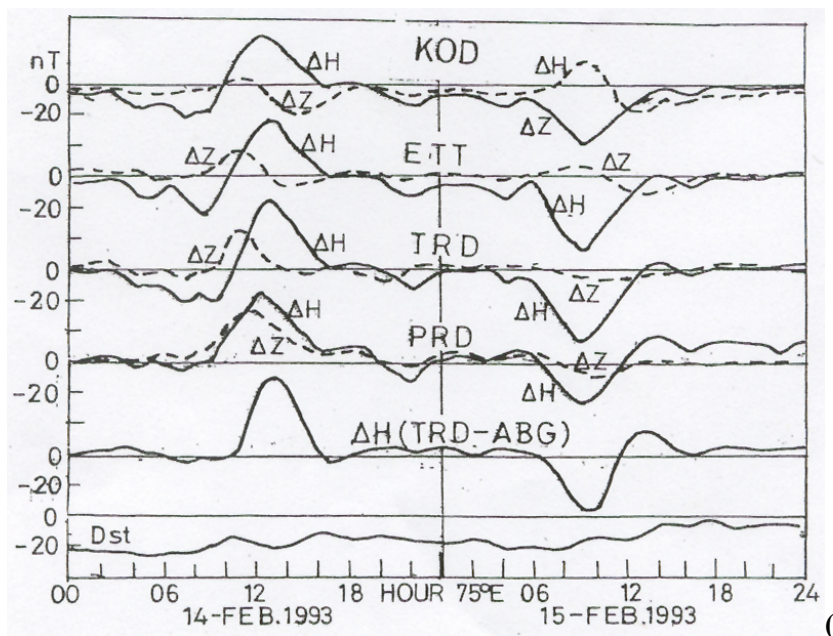

(b)

Fig. 7. Daily variations of $\Delta H$ and $\Delta Z$ at PRD, TRD, ETT and KOD as well as $\Delta H$ (TRD-ABG) on normal and counter electrojet days.

become trapped between the Earth's field lines and oscillate between high north and south latitudes at the same time spiraling around the field lines. Due to the decreasing magnitude of the mean magnetic field along the field lines, the particles drift normal to field lines, the electrons eastward and the positive charged particles westward thereby forming a westward ring current at an altitude of 3-4 Earth radii. This ring current drastically reduces the magnetic field at lowand middle-latitude stations around the Earth. With time, the 


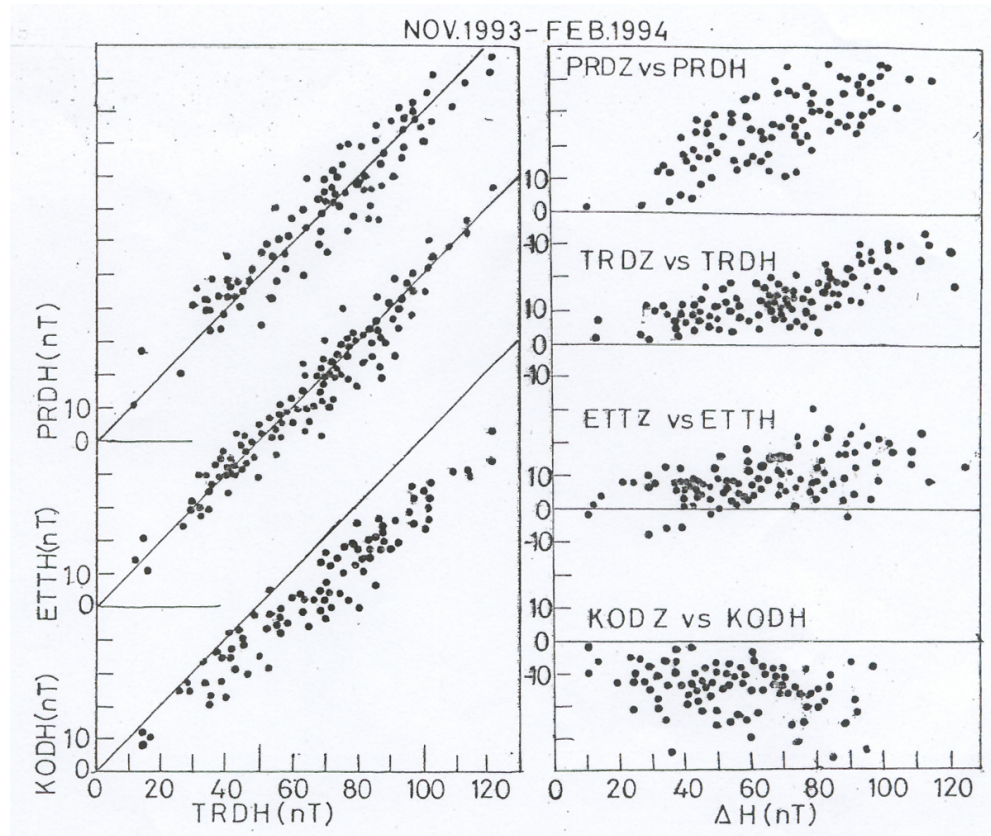

( a)

(b)

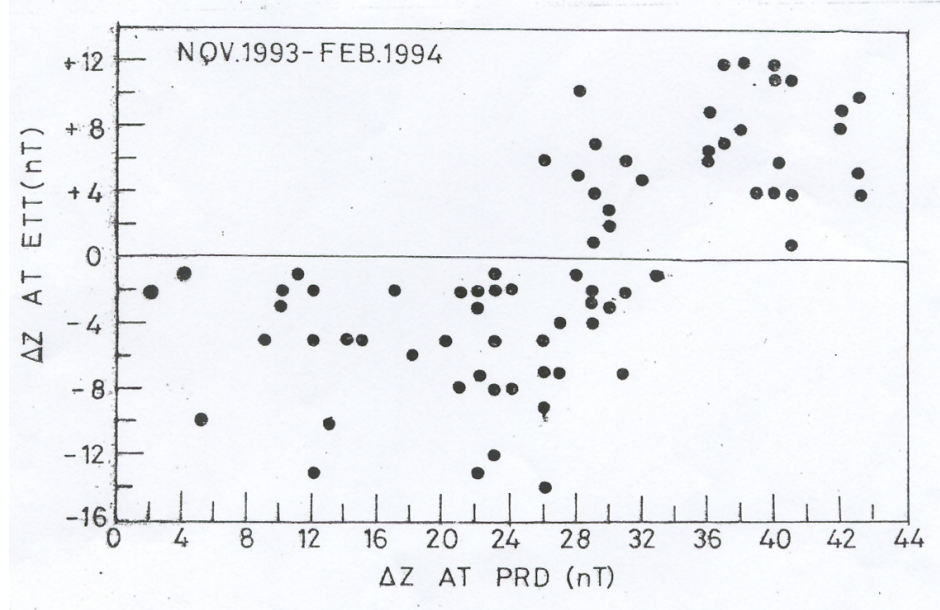

(c)

Fig. 8. (a) Mass plot of $\Delta H$ on individual days at PRD, ETT and KOD versus corresponding $\Delta H$ at TRD for the period November $1993-$ February 1994. (b) Mass plot of $\Delta Z$ versus corresponding $\Delta H$ at each of the stations PRD, ETT and KOD for the period November 1993-February 1994. (c) Mass plot of $\Delta Z$ at ETT against $\Delta Z$ at PRD during the period November 1993-February 1994.

charged particles recombine and the magnetic field observed at ground recovers back to normal values. The strength of this ring current is well indicated by the so-called $D_{s t}(H)$ index. The storm time variation is computed by removing the normal Sq variations from the value of $H, \mathrm{D}$ and $Z$ on the days following the SSC. The storm time variation, denoted as $D_{s t}$ variation, consists of a strong positive impulse due to SSC, a phase which extends for a couple of hours when $\Delta H$ is above normal and this is called the initial phase. The next phase is called the main phase, during which $\Delta H$ drops rapidly by a few $100 \mathrm{nT}$ on occasions and this phase lasts for a few hours. It is followed by the recovery phase that extends over 1-3 days when the field recovers slowly to normal values. The storm time variations are very important at low latitudes due to the deformations of the ionospheric current and the induced current during this period. This is further marked by the fact that the inductions are due to a rather uniform and very wide source field in contrast, with the induction due to the equatorial electrojet current which represents a non-uniform source field to limited spatial extent. The storm time variation of $Z$ shows a spectacular large decrease in $Z$ at Indian equatorial electrojet stations during the middle of the main phase about three hours before the peak decrease in $H$ (Rastogi, 2001). 


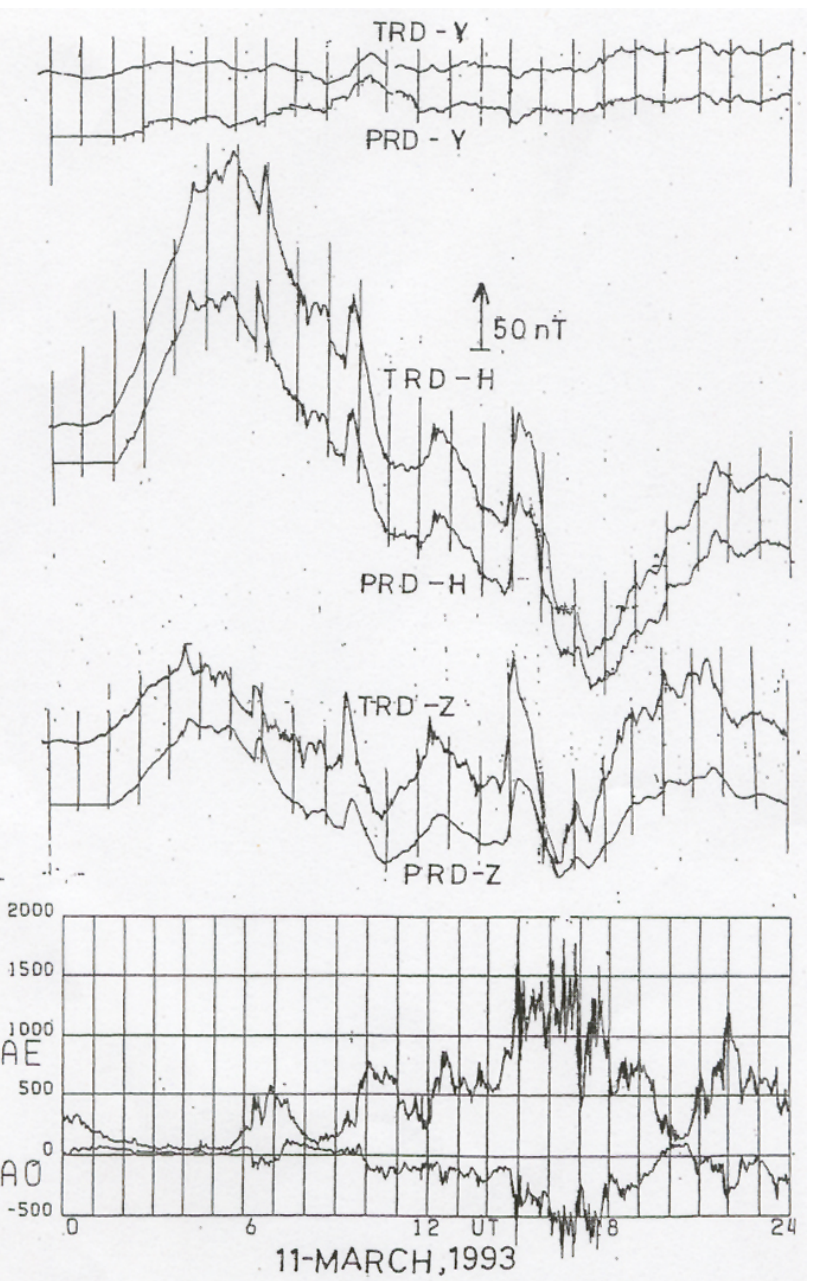

Fig. 9. Magnetograms at PRD and TRD on 11 March 1993 showing the effect of SSC on the $H, Z$ and $Y$ fields.

In Fig. 10 the storm time variation of $H, Y$ and $Z$ fields at TRD and PRD are shown on 4 to 6 April 1993 associated with the magnetic storm of SSC type starting at 19:33 LT on 4 April 1993. The variations of $D_{s t}$ and AE indices are also shown for comparison. The decrease in $D_{s t}$ and the increase of AE began immediately after the SSC with no initial phase of the storm. The large decrease in AE began immediately after the SSC with no initial phase of the storm. The large decrease in the $H$ field during the main phase is seen to be associated with a large decrease in the $Z$ field at both stations. The $H$ field at TRD and PRD had decreased by more than $160 \mathrm{nT}$. The $Z$ field also decreased by $160 \mathrm{nT}$ at TRD and by $125 \mathrm{nT}$ at PRD. In this case TRD response is also larger than PRD. It is interesting to note that the minimum of the $Z$ field was well before that of the $H$ field, more precisely it was at the time when the gradient of the $H$ field decrease was fastest, similar to the quiet day behaviour.

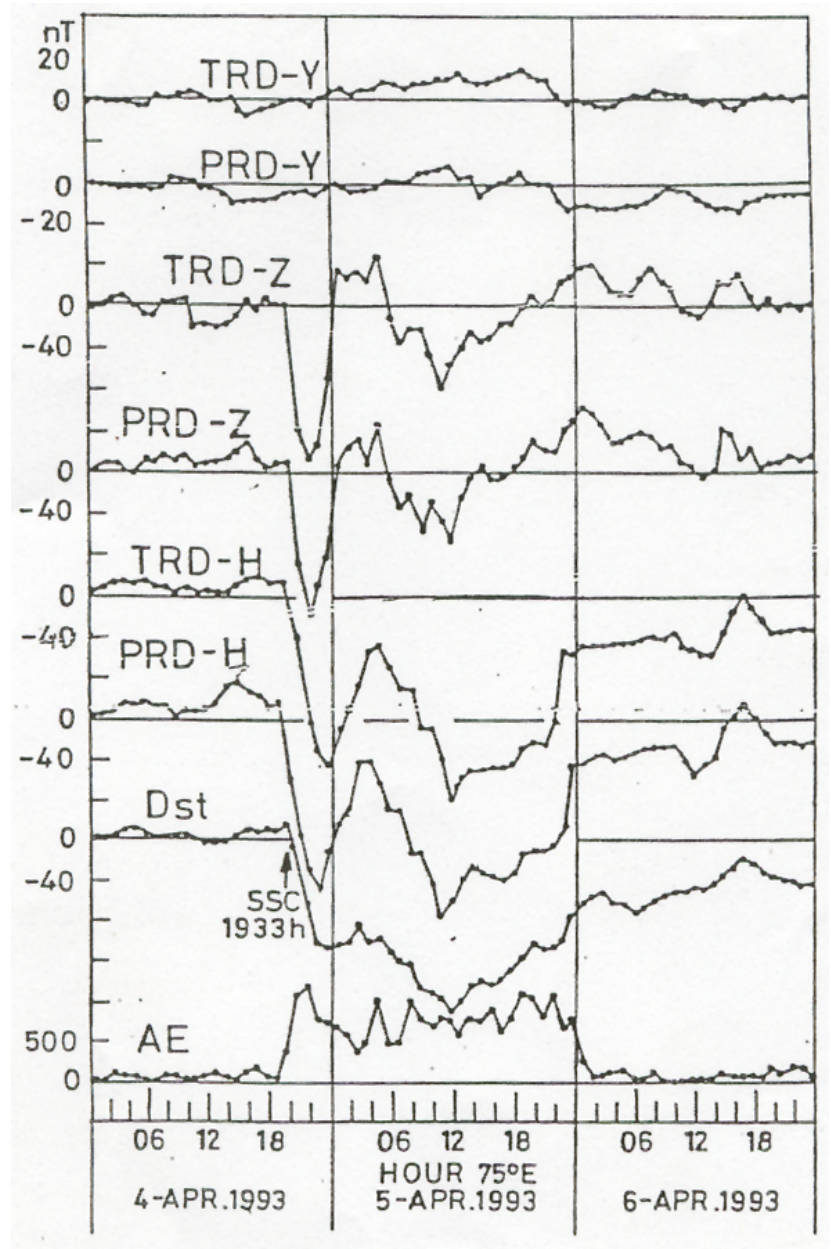

Fig. 10. Storm time variations of $H, Y$ and $Z$ fields at PRD and TRD during the magnetic storms starting at 19:33 LT on 5 April 1993.

\section{Discussion}

A network of four geomagnetic observatories in India at Trivandrum, Ettayiapuram, Kodaikanal and Annamalainagar within the equatorial electrojet belt have been in operation for more than twenty years. These data are supported by vertical incidence ionospheric soundings at Trivandrum (Thumba) and Kodaikanal. Various other ground-based ionospheric experiments, such as spaced receiver method of ionospheric drift, total electron content measurements using satellite radio beacons, VHF radar Doppler measurements, rocket instrument launching and other similar experiments have been undertaken in India. These experiments have produced voluminous reports on different properties of equatorial electrojet current and irregularities in the Indian region. Unfortunately, most of these observations refer to the ionosphere north of the magnetic equator. Some of the interpretations of the data may be inconclusive due to the lack of data from the region south of the equator.

The geomagnetic field $H, \mathrm{D}$ and $Z$ data from Peredinia, Sri Lanka fill up some of the lacunae. The result of the 
analysis reported here show that the quiet as well as disturbed day variations are very coherent at Peredinia and stations north of equator. Remarkably, the short period variations due to solar flare and sudden storm commencements are again very similar at the two stations in Sri Lanka and in India. It is interesting to note that the abnormal variations of the vertical field $Z$ at Trivandrum is reflected in similar ways at Peredinia.

Srivastava and Sanker Narayan (1970) suggested only qualitatively that the abnormal variations of the $Z$ field at Indian observatories are due to coastal effects. Takeda and Maeda (1979) ascribed anomalies in $H$ and D components during disturbed periods as due to channeling of the current through the shallow waters of the Palk Strait $(\mathrm{d}<100 \mathrm{~m})$. However, Papamastorakis and Harendel (1983) showed that these currents do not have any significant role at the periods concerned. Nityananda et al. (1977) suggested the abnormal $Z$ field at magnetic observatories in Peninsular India is due to the channeling of induced current through the Palk Strait and around the southern tip of the Indian Peninsula. Rajaram et al. (1979) introduced the idea of a conducting channel in the lower crust or upper mantle between India and Sri Lankan Island. Nityananda and Jayakumar (1981) gave arguments for the conjecture that zones of high electrical conductivity exist in the crust which are related to tectonic and mineral influences.

Mareschal et al. (1987) have reviewed the present views on the induction models of southern India and the effect of offshore geology. They suggested a combination of crustal conductors located in the Indo-Ceylon graben and underneath the Comorin Ridge that reproduces the observations at periods of 50-100 min. In so far as channeling is concerned, daytime variations do not help to define the location of conductors any better than nighttime data.

Arora (2000) tried to model the variations of $H$ and $Z$ fields at Indian stations by suggesting a conductor $30 \mathrm{~km}$ half width at a depth of $25 \mathrm{~km}$ in the Palk Strait. He used the model of equatorial electrojet (at the time of its peak value) for the 5 IQ days of February 1992. He computed the profiles of $\Delta H$ and $\Delta Z$ produced by the channeled current located at a depth of $25 \mathrm{~km}$ with a half width of $30 \mathrm{~km}$ and current density one-third of the external EEJ at midday. Combining the effect of the channel current and EEJ current effects he obtained good correlation with the observed $\Delta H$ and $\Delta Z$ ranges at Indian stations. However, the spatial dimensions of the conductor assumed and the source current in the ionosphere are very different. Further, all calculations made by him refer to noon time and therefore this cannot be compared with the range of $Z$ field which usually maximizes at $\sim$ 09:00 LT and minimizes at $\sim$ 15:00 LT, with a zero value at noon at the electrojet stations in India. All models by Chapman (1951) or of Onwumechilli (1967) a priori assume an infinite extension of the ionospheric current which is not valid for calculating the effect of a conductor limited in the $\mathrm{E}-\mathrm{W}$ direction. Lastly, the latitude variations of $H$ and $Z$ on the southern side of the equator do not fit with the observations at Sri Lanka. It is concluded that the idea of a very small conductor, compared to the dimension of ionospheric current, cannot explain the observed anomalies of the vertical field in the Indo-Sri Lanka sector.

Kumaratanam (1987) discussed pulsations in the geomagnetic field in the period 200-600 s recorded at Kodaikanal in the northern section and Hikkaduwa in the southern section of Sri Lanka. They found a high positive value of $\Delta Z / \Delta H$ at Hikkaduwa similar to those at Trivandrum. The dip latitude of Hikkaduwa was more than $2^{\circ} \mathrm{S}$ and should be close to the edge of the electrojet belt, and the effect of the induced current in the Palk conductor should be negative $\Delta Z$ compared to positive $\Delta Z$ at ETT. This is a good confirmation that the induction effects to be similar and of same phase at all stations from ETT to extreme south of Sri Lanka island.

A very cogent suggestion in this field was made by Nityananda and Jayakumar (1981) that Sri Lanka has one of the largest deposits of graphite in the world, and the high electrical conductivity of the mineral could be stronger source of induced current.

In conclusion, it is suggested that we have to modify the role of the Palk conductor and think of a much wider conductive region around southern India and Sri Lanka. Relocation of a few stations in Sri Lanka and India by the Kyushu global network of magnetometers would prove to be of tremendous help in solving this problem of electromagnetic induction.

Acknowledgements. Geomagnetic data from different observatories were taken from yearbooks published by respective institutes. The IMF data were taken from IMF Data Handbook by J. F. King of NASA, USA. The magnetograms for Trivandrum were taken from the CD ROM kindly supplied by T. Iyemori of WDC2, Kyoto, Japan. The author expresses his gratitude to both the referees for numerous suggestions which much improved the whole paper. Thanks are due to Indian Space Research Organisation for the research project and to the Physical Research Laboratory and Gujarat University for providing facilities.

Topical Editor M. Lester thanks two referees fopr their help in evaluating this paper.

\section{References}

Arora, B. R.: Effects of anomalous electromagnetic induction in the source characterization of equatorial geomagnetic fluctuations, J. Ind. Geophys. Union, 4, 29-39, 2000.

Carlo L., Singh, B. P., Rastogi, R. G., and Agarwal, A. K.: The induced effects of geomagnetic variations in the equatorial region, J. Geophys., 51, 199-205, 1982.

Chandra, H. and Rastogi, R. G. : Horizontal drifts in the ionospheric E and $F$ regions over Thumba, J. Atmos. Terres. Phys., 31, 12051215, 1969.

Chandra H., Misra, R. K. and Rastogi, R. G.: Equatorial ionospheric drift and the electrojet. Planet. Space Sci., 19, 1497-1503, 1971.

Chapman, S. and Bartels., J: Geomagnetism, Vol. I, Clarendon press, Oxford 1940.

Chapman, S.: The equatorial electrojet as detected from the abnormal current distribution above Huancayo, Peru and elsewhere, Arch. Met. Geophys. Bioklimatol. Ser. 4A, 368-390, 1951. 
Egedal, J.: The magnetic diurnal variations of the horizontal force near the magnetic equator, Terr. Magn. Atmos. Electr., 52, 449451, 1947.

Fambitopaye, O.: Etude des effects magnetiques de electrojet equatorial Bulletin No.14, OSTROM-Paris, 1976.

Forbush, S. E. and Casaverde, M.: Equatorial electrojet in Peru, Carn. Inst. Washington Publ., 620, 1961.

Gouin, P. and Mayaud, P. N.: A propos des existence possible d'un contre electrojet aux latitudes magnetiques equatoriales, Ann. Geophys., 23, 41-47, 1967.

Kumaratanam, K.: Short period geomagnetic variations at two stations in Sri Lanka and their relation to channeling of induced currents through a conducting region beneath the Palk Strait, Phys. Earth. Planetary Interiors, 49, 343-349, 1987.

Mareschal, M., Vasseur, G., Srivastava, B. J., and Singh, R. N.: Induction models of southern India and the effect of off-shore geology, Phys. Earth. Planet. Inter., 45, 137-148, 1987.

Mc Nish, A. G.: Bull 10. Int. Assoc. Magn. Transaction of Edinburgh meeting, Copenhagan, 271-280, 1937.

Nityananda N., Agarwal, A. K., and Singh, B. P.: Induction at short period on the horizontal field variation in the Indian Peninsula, Phys. Earth Planet. Int., 15, 5-9, 1977.

Nityananda, N. and Jayakumar, D.: Proposed relation between anomalous geomagnetic variations and tectonic history of South India, Phys. Earth. Planet. Int., 27, 223-228, 1981.

Onwumechilli, C. A.: Recent measurements of the magnetic field of the equatorial electrojet in Nigeria, J. Geophys. Res., 68, 2421, 1963.

Onwumechilli, C. A.: Geomagnetic variation in the equatorial zone, in: Phys. Geomg. Phenomena, edited by Matsushita, S. and Campbell, W. H., Chapter III-2, 425-507, 1967.

Papamastorakis, I. and Harendel, G.: An analogue model of the geomagnetic induction in the south India ocean, J. Geophys., 52, 61-68, 1983.

Pramanik S. K., Narayanan, S. Y.: Diurnal magnetic variations in equatorial regions, Ind. J. Meteor. Geophys., 3, 212-216, 1952.

Pramanik, S. K. and Hariharan, P. S.: Diurnal magnetic variations near the magnetic equtor, Ind. J. Meteor. Geophys., 4(4), 353388, 1953.
Rajaram M., Singh, B. P., Nityananda, N., and Agrawal, A. K.: Effect of the presence of a conducting channel between India and Sri Lanka Island on the features of the equatorial electrojet, Geophys. J. R. Astr. Soc., 56, 127-138, 1979.

Rastogi, R. G.: The equatorial electrojet in magnetic and ionospheric effects. Geomagnetism Vol. 3, 461-525, edited by Jacobs, J., Academic Press Ltd., 1989.

Rastogi, R. G.: Electromagnetic induction due to SSC at equatorial eletrojet stations, Ind. J. Rad. Space Phys., 28, 253-263, 1999.

Rastogi, R. G.: Disturbance time variations in geomagnetic vertical field at Indian equatorial electrojet, Current Science, 80, 10561059, 2001.

Rastogi, R. G.: Electromagnetic induction by equatorial electrojet in Indian longitudes, Geophys. Journal International, in press, 2004.

Rastogi, R. G.and Stening, R. J.: On the eastward geomagnetic field variations at electrojet stations, Ind. J. Rad. Space. Phys., 31, 6774, 2002.

Rastogi R. G., Chandra, H., and Chakravarty, S. C.: The disappearance of equatorial Es and the reversal of electrojet current, Proc. Ind. Acad. Sci., 74, 6-67, 1971.

Siebert M. and Kertz, W.: Zur Zerlegung eines lokalen erdmagnetischem Felds in ausseren und inneren Anteil, Nachr. Akad. Wiss. Gattingen, Math-Physik. K1. No. 5, January 1957.

Srivastava, B. J. and Sankernarayan, P. V.: Anomalous geomagnetic variations in the peninsular India-ocean effect and upper mantle conductivity structure, Bulletin of National Geophysical Research Institute, 8, 125-134, 1970.

Takeda M. and Maeda, M.: Effect of the coastline configuration of south India and Sri Lanka on the induced field at short period, J. Geophys., 45, 209-218, 1979.

Woodman R. F.: Vertical drift velocities and east-west electric field at the magnetic equator, J. Geophys. Res., 75, 6249-6259, 1970.

Yacob A. and Khanna, K. B.: Geomagnetic Sq variations and parameters of the Indian electrojet for 1958-1959, Ind. J. Met. Geophys., 14, 470-477, 1963. 